\title{
Las relaciones entre el neoliberalismo y la democracia
}

A más de un apologista del capitalismo se le ha ocurrido parafrasear a Marx a propósito de aquella frase del Manifiesto Comunista en la que se dice que "un nuevo fantasma recorre el mundo: el comunismo". Sin embargo, los apologistas convertidos de la noche a la mañana en sociólogos, politólogos o historiadores han cambiado la palabra "comunismo" por "neoliberalismo", con lo cual el fenómeno nuevo y dominante en las sociedades actuales vendría a ser el "fantasma neoliberal". ¿Qué duda cabe que el neoliberalismo es el fenómeno dominante en la época actual? Es dominante en cuanto que, con la crisis de los proyectos de economía planificada adscritos a los socialismos reales, la economía de mercado y sus legitimaciones ideológicas se imponen sin resistencia alguna por el mundo. Es decir, en el momento actual, son pocos los que se atreven a poner en duda las virtudes del mercado como asignador y optimizador de recursos; y, asimismo, son muchos los dirigentes políticos, intelectuales y empresarios que abogan por la no intervención del Estado en la economía y por una extrapolación de las reglas del mercado hacia otras esferas de la realidad social.

Pero que el neoliberalismo sea algo absolutamente novedoso no se puede sostener tan fácilmente: se trata de un nuevo liberalismo que hunde sus raíces en el viejo liberalismo de Adam Smith, al cual despoja de su talante ético. Como señala Amartya Sen "de hecho, en la economía moderna, es precisamente la reducción de la amplia visión smitheana de los seres humanos lo que pueda considerarse como una de las mayores deficiencias de la teoría económica contemporánea. Este empobrecimiento se encuentra íntimamente relacionado con el distanciamiento de la economía y de la ética" (Amartya Sen, Sobre ética y economía, México, 1987, p. 45).

Este distanciamiento entre economía y ética es sumamente acusado en el pensamiento neoliberal. Es por ello que Luis de Sebastián llegó a definir al neoliberalismo como un no-liberalismo, es decir, como un pensamiento económico que no se parece "en nada al liberalismo económico clásico de los autores de la economía política británica de los siglos XVIII y XIX" ("El neoliberalismo una negación del liberalismo", Realidad Económico-Social, II (11), p. 419). Y ello porque si para el liberalismo clásico los ideales fundamentales son la libertad, la igualdad y la fraternidad, para el neoliberalismo lo esencial es el "darwinismo social". Un mundo en el que predomina el darwinismo social, "la libertad no cuenta porque todo está determinado; la igualdad es totalmente indeseable, porque el avance de la especie se basa en la diferencia de suertes y oportunidades, en la superioridad de algunos sobre los demás; y la fraternidad es una debilidad imperdonable, que no puede significar nada real en un mundo competitivo donde el hombre es para el hombre un lobo feroz" (Ibid., p. 435). El neoliberalismo es, pues, "la negación del liberalismo" (Ibid., p. 419). 
Por lo demás, si bien el abandono de la perspectiva ética, algo inconcebible en la economía política clásica, constituye una de las características esenciales del pensamiento neoliberal -una característica que permite conceptuarlo como un no-liberalismo-, hay algunas notas que sí permiten inscribirlo en el horizonte del pensamiento liberal clásico e incluso permiten entenderlo como un pensamiento que radicaliza - y actualiza - las tesis más "salvajes" de aquél.

Ante todo, tenemos una exacerbación del "individualismo posesivo" ya apuntalado por John Locke, el cual supone que la humanidad del individuo se juega en el poseer y consumir insaciablemente; en segundo lugar, tenemos una radicalización de la tesis de hobbseana del hombre como lobo para el hombre, que supone una competencia sin cuartel entre los individuos, en la cual cualesquiera de los medios utilizados posee una legitimidad indiscutible si contribuye a doblegar al adversario y a triunfar en la "lucha por la existencia"; $y$, en tercer lugar, nos las habemos con una absolutización del mercado, es decir, con una apuesta por el automatismo de las reglas de la oferta y la demanda como generadoras —cuanto más se dejen a su propia lógica y no sean perturbadas por ninguna ingerencia "estatista"- de riqueza, bienestar y desarrollo.

En resumen, el neoliberalismo es nuevo en cuanto que supone una renuncia a los ideales del viejo liberalismo; pero no es tan nuevo si asumimos que algunas de sus tesis más radicales hunden sus raíces en Locke, Hobbes e incluso el propio Smith. Hay, asimismo, dos aspectos adicionales que hacen del neoliberalismo algo distinto respecto del liberalismo: su orientación práctica, esto es, su propósito expreso de traducirse en una serie de políticas económicas, y su pretensión de extender la lógica del mercado a todas las demás esferas de la realidad social.

En lo que se refiere a su orientación práctica, el neoliberalismo es un pensamiento cuyo propósito es traducirse en un conjunto de políticas económicas a ser adoptadas por los equipos gubernamentales y privados. Entre las políticas más relevantes se encuentran las de ajuste estructural, las de apertura externa y las de reducción de los apa- ratos estatales, cuyos objetivos son estabilizar unas economías en crisis, propiciar su inserción en el mercado mundial y eliminar las interferencias "estatistas" en la dinámica del mercado, asumiendo que el Estado ha sido el responsable de la crisis económica, la inflación y la falta de competitividad externa.

En la concepción neoliberal se trata de regular la totalidad de la vida humana, según las reglas del mercado. Así, el individuo es entendido como un ser de "elección racional" (rational choice), es decir, como un ser cuyo comportamiento está regulado por un cálculo de costos y beneficios. En otras palabras, cada individuo, en sus relaciones con los demás, busca maximizar sus utilidades, minimizando sus costos. En el plano político, los partidos son entendidos como oferentes de proyectos ideológico políticos que compiten entre sí por venderse a los votantes, quienes con su voto compran la mercancía política de su preferencia. La política, pues, funciona según las reglas del mercado: los

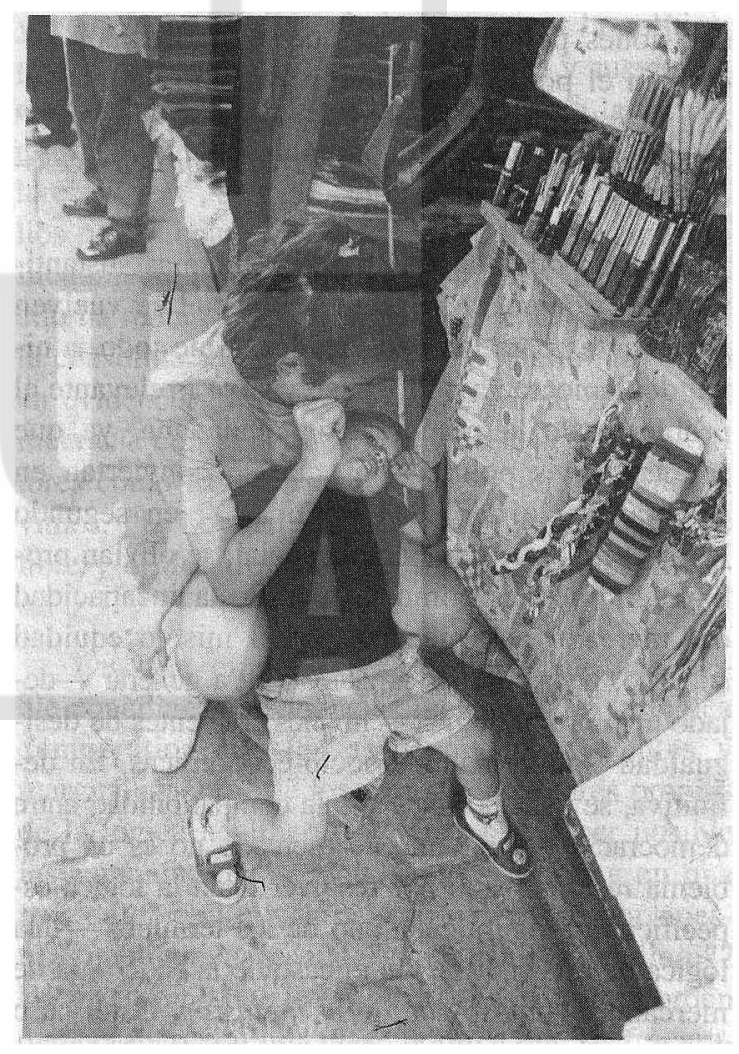


electores son los compradores y los partidos son los vendedores; no hay compromiso de principios entre unos y otros, sino la habilidad de los segundos para promocionar sus programas y la libertad de los primeros para comprarlos por un determinado período.

En suma, como sostiene Milton Friedman, "[El libro] Libertad de elegir (Hacia un nuevo liberalismo económico) trata el sistema político de un modo simétrico al económico. Ambos se consideran mercados en los que el resultado se determina a través de la interacción de personas que persiguen sus propios intereses individuales en vez de los objetivos sociales que los participantes juzgan ventajoso anunciar... La libertad política llegó con el mercado libre y el desarrollo de las instituciones capitalistas" (citado por R. Villarreal, R., La contrarrevolución monetarista. Teoría, política $e$ ideología del neoliberalismo, México, 1986, p. 461). Y, una vez que la política ha sido "colonizada" por el mercado, los neoliberales nos dicen que la democracia es nada más que un método. Un método, como dice J. Schumpeter, "para llegar a las decisiones políticas, en el que los individuos adquieren el poder de decidir por medio de una lucha de competencia por el voto del pueblo" (Capitalismo, socialismo y democracia, Barcelona, 1983, p. 343).

Como podemos ver, pues, problemas sustantivos de la democracia política y social se vuelven irrelevantes para los neoliberales. Ante todo, a nivel de democracia política, se vuelve irrelevante el problema de la participación ciudadana, ya que son las élites políticas las que se convierten en gestoras de la actividad política. $Y$, en segundo lugar, a nivel de democracia social, se obvian problemas cruciales como la manifiesta incapacidad del mercado para generar por sí mismo equidad social o, peor aún, su capacidad para generar —dejado a su propia lógica - niveles crecientes de desigualdad y marginalidad socio-económicas. En definitiva, se pasa por alto que la compatibilidad entre democracia y economía de mercado no es un problema resuelto, sino por resolver dada la lógica específica que rige a cada uno de los términos - una lógica de la exclusión, en el caso de la economía de mercado, y una lógica de la inclusión, en el caso de la democracia.

¿Cómo se confrontan estas lógicas en una sociedad concreta como la salvadoreña? ¿Cuáles son las exigencias de la democracia y cuáles las del mercado? ¿Cuál es el influjo de la economía en la política? Ese influjo, ¿potencia la democracia o más bien la socaba? En el caso de El Salvador, ¿es compatible la lógica neoliberal con la lógica de la participación?

Pues bien, en nuestro país, desde la firma de los acuerdos de paz, en 1992, la dinámica social y laboral ha estado fuertemente influenciada por la dinámica económica, la cual no sólo no ha revertido parte de sus logros macroeconómicos hacia los sectores más desfavorecidos de la sociedad, sino que incluso, con sus exigencias, ha agravado las condiciones de vida de la mayor parte de la población.

En lo que se refiere al impacto de la economía en la política, no cabe duda que la lógica neoliberal, al agravar las desigualdades socio-económicas, se ha convertido en un obstáculo importante para avanzar en el proceso de democratización en cuanto que, por un lado, ha puesto límites al fortalecimiento de la participación política; y, por el otro, ha socavado las bases de la edificación de la ciudadanía. Qué duda cabe que cuando la mayor parte de la población de un país dedica la mayor parte de su esfuerzo cotidiano a tareas que le permitan sobrevivir la preocupación por la polis pierde relevancia, es decir, estamos ante una de las causas explicativas de la desafección política.

Pero el problema de la democracia en sociedades como la salvadoreña no estriba sólo en el desinterés popular por la política, sino en que la "lucha por la existencia" cotidiana se torna feroz, violenta y desesperada, en la cual el fin perseguido justifica los medios utilizados, sean éstos cuales fueran. En este marco, el reconocimiento del otro, de sus derechos y deberes, así como la asumpción de las propias responsabilidades hacia ese otro y hacia el conjunto de la sociedad se vuelven asuntos que no conciernen a nadie en particular y que, peor aún, cuando son puestos en práctica o exigidos aparecen - para la gran mayoría de la población- como algo fuera de lugar, como una insen- 
satez. Es decir, los requisitos básicos para la formación de la ciudadanía son rechazados y violentados por la mayor parte de la sociedad; y ello, en buena medida, está motivado por el ethos vital exigido e impuesto por la dinámica económica, cada vez más regida por la lógica neoliberal.

La democracia, entendida como un régimen político en el cual se garantiza la igualdad de los ciudadanos a través de la participación creciente de éstos en los asuntos de la polis, no se puede afianzar debidamente si aquella participación no tiene lugar, al igual que si no se construye la ciudadanía, entendida esta última como el compromiso de cada uno de los miembros de la sociedad con el reconocimiento y respeto del otro, así como con el cumplimiento y aceptación de las leyes. El neoliberalismo, al agudizar las desigualdades socio-económicas, entra en contradicción con las exigencias de la democracia. En los últimos años, esa contradicción ha aflorado con gran fuerza en nuestro país. El empobrecimiento de las mayorías populares, como consecuencia de las medidas económicas neoliberales, ha puesto límites infranqueables a la potenciación de la participacion política y a la formación de la ciudadanía, esto es, a la consolidación del proceso de instauración de la democracia.

Por lo demás, el impacto negativo del neoliberalismo sobre la instauración democrática ha sido sólo uno de los aspectos del proceso histórico salvadoreño desde la firma de los acuerdos de paz. Otro aspecto al que conviene prestar atención más detenidamente tiene que ver con la fragilidad del sistema político, la cual se ha puesto de manifiesto en su incapacidad para hacer de intermediario entre las exigencias de la lógica económica neoliberal y las de la sociedad, especialmente la de aquellos sectores más golpeados por las medidas de ajuste, las reformas impositivas y la reducción estatal.

Si la contradicción apuntada entre el neoliberalismo y la democracia ha puesto de relieve la relación, no del todo coherente, entre economía y política, la segunda ha expresado no sólo la tensión existente entre economía y sociedad, sino la debilidad de los mecanismos de intermediación y resolución de conflictos entre ambos polos. Es decir, nos encontramos con los límites de la política para encauzar institucionalmente las demandas y el descontento social, consecuencia de las desigualdades socio-económicas, agravadas por la economía neoliberal.

Así, en los últimos años, el neoliberalismo en El Salvador no sólo ha debilitado la política al minar las condiciones básicas para la participación e incidir negativamente en la construcción de la ciudadanía, sino que —al profundizar la pobreza y constreñir los mecanismos de compensación diseñados en el pasado para paliar sus efectos- ha propiciado demandas y protestas sociales ante las cuales el sistema político se ha visto imposibilitado para responder. Al final, esas demandas lo han desbordado. Con ello, el fantasma de la ingobernabilidad se ha hecho presente, la desconfianza popular en las instituciones ha crecido y la credibilidad en la política y los políticos ha disminuido sensiblemente.

A los obstáculos para la participación política impuestos por las urgencias cotidianas de sobrevivencia, se ha añadido un desinterés por la política, motivado por lo poco o nada que ésta y sus gestores pueden ofrecer; a los obstáculos para la formación de la ciudadanía, inducidos por la "lucha por la existencia", se ha añadido el rechazo hacia aquellos que, amparados en la ley, se han enriquecido ilícitamente y han traficado con influencias. Todo ello ha redundado en un sensible estancamiento en la consolidación democrática. Todo ello ha puesto en evidencia lo difícil que resulta conciliar la democracia con el neoliberalismo, a despecho de autores como Milton Friedman para quien, como ya vimos, "la libertad política llegó con el mercado libre y el desarrollo de las instituciones capitalistas".

$\mathrm{Y}$ es que, en definitiva, ¿cómo puede ser posible conciliar las exigencias inclusivas de la lógica democrática con las exigencias excluyentes y marginalizadoras de los sectores populares propias de la lógica neoliberal? ¿Cómo puede ser posible instaurar una democracia social y política en una país en el cual el capitalismo defendido por nuestros neoliberales es un "capitalismo maquilero"? En fin, ¿cómo puede ser posible instaurar un orden democrático con una clase política que ha fracasa- 
do en su función de intermediaria entre las demandas de la sociedad, cada vez más golpeada por las políticas neoliberales, y las exigencias del merca- do, cada vez más excluyente y depredador de los recursos naturales y sociales?

Luis Armando González 